\title{
Long-term analysis of irrational water use processes based on cartographic materials and remote sensing data
}

\author{
Andrey Medvedev ${ }^{\mathrm{a}, *}$, Natalia Alekseenko ${ }^{\mathrm{b}}$, Natalia Telnova ${ }^{\mathrm{a}}$, Alexander Koshkarev ${ }^{\mathrm{a}}$ \\ ${ }^{a}$ Institute of geography Russian Academy of Sciences, a.a.medvedeff@ gmail.com, natalia.telnova@ gmail.com, \\ akoshkarev@yandex.ru \\ ${ }^{b}$ Lomonosov Moscow State University,valtuz@mail.ru \\ * Corresponding author
}

Keywords: Shoreline changes, ultra-high resolution, UAV, mountain lakes

\begin{abstract}
:
Assessment and monitoring of environmental features based on large-scale and ultra-high resolution data, including remote sensing data, which have advantages in the repeatability of information and the speed of processing of incoming data, often face issues of completeness and duration of time series in retrospective analysis. Cartographic materials and remote sensing data allow monitoring for rapidly changing natural and anthropogenic features in the study areas, but very often face a problem when an event or phenomenon occurred many years ago and it is necessary to make a complete chronology.

Ultra-high-resolution data, remote sensing data and the results of the subsequent geoinformation analysis are widely used to solve problems in a number of socio-economic areas of territorial development, in particular:

- in environmental studies - identification of local sources of water pollution, the consequences of their impact on ecosystems, synthetic assessment of the ecological state of the territories and their comfort;

- in the management of various resources, including water - determination of biological productivity of water bodies, identification of water bioresources, detection of anthropogenically provoked and natural changes in water mass, implementation for glaciological studies, etc.

Within the framework of the current study, a multi-time analysis of the water area and the coastal strip of Lake Sevan (the Republic of Armenia) at an altitude of about $1900 \mathrm{~m}$ above sea level, was carried out. The lake has repeatedly been subjected to changes in the water level of the reservoir in the past. The 1930s and in the period between 1949 to 1962 were noted by the most intense drop in water level (more than 10 meters). In the 1990s, there was a slight increase in the level, and then until 2001, the level of the lake continued to decrease.

The main factors affecting aquatic ecosystems and the overall ecological status of the lake are:

1. Repeated changes in the water level of the reservoir in the past and its expected fluctuations in the future.

2. The uncontrolled discharge of harmful substances caused great damage to the lake, which affected the water quality and biodiversity of this unique natural site.

3. Untimely cleaning of flooded forests, which increases the risk of eutrophication of the lake.

4. The poorly organized system of waste disposal and unauthorized landfills of municipal solid waste, as well as animal waste.

5. Unauthorized construction of recreational facilities and capital structures in the coastal and water protection zone which may be flooded.

The information support of the study is based on the materials of satellite imagery from the worldview2, SPOT 5/6, Resurs-P, Canopus-B, materials from the international space station (ISS), materials of archival aerial photography and data obtained from the UAVs, in combination with other map data sources in the range of scales 1:5 000 - 1:100 000, including digital topographic maps, land use maps, statistical and literary data. In fact, cartographic materials and remote sensing data provide a time history of 75 years, from large-scale topographic maps of 1942-1943 to highly detailed images of 2017-2018.

According to the results of the study, it was possible to establish the position of the coastline for different time periods. The period between 1949 and 1962, when there was the most critical drop in the water level, was especially interesting and had not been studied before. Archival aerial photographs for 1943 and 1963 allowed to reconstruct the position of the coastline for almost every year of irrational water use.
\end{abstract}

The study is supported by the RFBR project 18-55-05015 Arm_a. 